\title{
A Water Quality Assessment Tool for Decision Making, Based on Widely Used Water Quality Indices †
}

\author{
Mavromatidou Charoula, Trikilidou Eleni, Samiotis Georgios, Pekridis George, Lefteri Lefteris, \\ Tsikritzis Lazaros and Amanatidou Elisavet * \\ University of Western Macedonia, Environmental Chemistry and Water \& Wastewater Treatment Research \\ Laboratory, Koila University Campus, 50100 Kozani, Greece; xaroulam73@gmail.com (M.C.); \\ etrikilido@yahoo.com (T.E.); samiotis1982@hotmail.com (S.G.); pekridisg@gmail.com (P.G.); \\ lefteris1194@gmail.com (L.L.); tsikritzis@teiwm.gr (T.L.) \\ * Correspondence: eamanatidou@uowm.gr; Tel.: +30-24610-68015 \\ + Presented at the 4th EWaS International Conference: Valuing the Water, Carbon, Ecological Footprints of \\ Human Activities, Online, 24-27 June 2020.
}

Published: 12 August 2020

\begin{abstract}
Cross border areas face common challenges on water management, such as monitoring water demands and quality, because they share a common water basin for covering their water needs. This paper presents the first results of a new, accurate, sensitive and functional tool for assessing water quality, taking under consideration legislation and expert's opinion, created in frame of the SAVE-WATER, Interreg IPA II Cross-border Cooperation Programme Greece-Albania 2014-2020. The project addresses the open problems and challenges by promoting a transnational common strategy for drinking water management and a shared management policy among three Greek and two Albanian cross border regions.
\end{abstract}

Keywords: SAVE-WATER; water quality management tool; Aliakmon river basin

\section{Introduction}

The physico-chemical classification of an aquatic system is a complicated procedure due to the numerous parameters that may affect its water quality. An accurate and precise assessment of water quality requires the analysis of each and every chemical, physical and biological characteristic it may possess [1]. Such a list would be as long as the number of constituents analyzed, which may be anything from the 20-odd common constituents to hundreds. Moreover, such a list will make little sense to anyone except well-trained water quality experts [1; also, such an assessment will be prohibitively costly. Different water uses demand the analysis of different qualitative parameters with variations in their limit values and significance.

Cross border areas face common challenges on water management, such as monitoring water demands and quality, man-made and natural pressures and leakages/non-revenue water, mainly because they share a common water basin for covering their water needs. The need for a holistic solution to the problem of the transnational water management is obvious, but the existence of significantly varying approaches by the regional administrations, the lack of common monitoring protocols and surveys, the lack of proper, concrete and common strategies for efficient and effective management, and of a concrete action plan and policy, result in an inadequate monitoring water quality.

SAVE-WATER, an Interreg IPA II Cross-border Cooperation Programme (2014-2020) between Greece and Albania, addresses the aforementioned open problems and challenges by promoting a transnational common strategy for drinking water management and a shared management policy among three Greek and two Albanian cross border regions. Among the actions implemented is a 
pilot action, during which a smart low-cost, sensor-based transnational monitoring network will be developed and gradually expanded and tested. In the end, the proposed low-cost monitoring networks will provide the possibility to construct robust decision-making tools for managing both water quality and quantity.

A widely applied methodology for conveying the different physico-chemical parameters in one single expression is the calculation of a Water Quality Index (WQI), which is a number, a scale, a word, a symbol or a color that expresses the water quality of an aquatic system at a specific area in a specific period [2].

Horton (1965) developed the first WQI, which included ten common parameters widely used for water quality assessment, using weight coefficients [1]. This WQI classified water quality in a scale from 1 to 4. Brown et al. (1970) developed a WQI similar in structure to Horton's index, but with much greater rigour in selecting parameters, developing a common scale and assigning weights for which elaborate Delphic exercises were performed. This effort was supported by the National Sanitation Foundation (NSF). For this reason, Brown's index is also referred to as NSF-WQI. [1].

Since 1970, numerus WQIs have been developed worldwide, such as Prati's Implicit Index of Pollution (1971), O'Connor's (1972), Bhargava's (1983, 1985), Dinius's (1987), Smith's (1990), Wepener's et al. (1992), Oregon's Water-Quality Index (OWQI) (1983), The Canadian Water Quality Index (CCME, 2001), Said's et all. (2004), Boyacioglu's (2007) and Hanh's et al. (2011) [1].

According to Abbasi and Abbasi (2012), despite the plethora of indices which have been developed and used across the world it is not possible to say which index is the best or even list 'ten best' or 'twenty best' indices. One does find that some indices are more popular than some others, such as NSF-WQI and CCME WQI.

WQIs differentiate according to their calculation methodology and the included parameters. Their application presents restrictions, such as the use of specific quality parameters, which can lead to the omission of important data and the extraction of incorrect conclusions. Furthermore, many of the control parameters provided by the legislation, such as pesticides, halogenated hydrocarbons, heavy metals and pathogenic microorganisms are not included in the calculation of most water quality indices.

Over the last two decades, many researchers have undertaken studies where existing WQIs are applied for evaluating water quality in specific water systems. Moreover, several attempts have been made to improve existing WQIs, so as to adapt them to specific conditions or to modify them by reducing the number of included parameters. There have also been studies, mainly over the last decade, focusing on the comparative evaluation of different WQIs. This has received much attention lately since, although there is a large variety of WQIs available, there is not a globally accepted one. Therefore, the investigation of the effectiveness of a large number of WQIs in different environments and their comparative assessment are crucial to ensure that they respond the same, and subsequently, to be able to suggest the most appropriate one. It is concluded that different classification results may occur when a different WQI methodology is applied and therefore, great caution should be exercised in selecting a specific methodology to implement a water quality evaluation. Discrepancies arising among the different methodologies result from factors, such as the number and the combination of the quality parameters included in each index, as well as the mathematical formulas the index applies for transforming concentrations into sub-index values and aggregating individual sub-index scores [3].

This paper presents the first configuration results of a new, accurate, sensitive and functional tool (WQI) for assessing water quality, based on individual needs and local specificities of an area and by taking under consideration the legislation and the expert's opinion through direct communication. This new WQI is named $\Upsilon \Delta \Omega P$, which is the ancient Greek word for water. This work constitutes an optimized version of $\Upsilon \Delta \Omega$ PWQI, since its introduction in 2017 [4]. $\Upsilon \Delta \Omega P W Q I$ includes a sufficient number of monitoring parameters from different categories (bacteria, pesticides, heavy metals, nutrients, organic substances, etc.) based on experts' opinion and the latest guidelines of National, European and International legislation, while maintaining its sensitivity and 
consistency. The study also introduces the use of additional parameters in calculating a WQI and redefines their weight coefficients according to the current needs. All these data can be used by everyone involved in water quality management in order to modify $\Upsilon \Delta \Omega P W Q I$ based on their needs and specificities of their area. Furthermore, in this study, the results of $\Upsilon \Delta \Omega P W W Q I$ were compared with those of a modified NSFWQI [5], and of CCMEWQI [6], for the same data.

\section{Materials and Methods}

A literature review of Water Quality Indices, from the first one created (1965) until our days, was conducted for choosing the basic calculating equation for $\Upsilon \triangle \Omega P W Q I$. The selected equation is additive (Equation (1)); control parameters and legislation limits of water quality are changeable, which make the proposed WQI not only flexible to use, but also comparable to other indices. The equation of this new version of $\Upsilon \Delta \Omega$ PWQI has been modified since its previous version [4], in order to increase its sensitivity by taking into account the number of transgressions of legislation.

$$
W Q I=\frac{\sum_{i=1}^{n}[\operatorname{Average}(q i \times R W i)]+\sum_{i=1}^{n}[\mathrm{Ri}, \mathrm{e} \times \operatorname{Average}(q i, e \times R W i)]}{\sum_{i=1}^{n} R W i}
$$

where: $q i=$ Sub-index of sample for $i$ parameter; $q i, e=$ Sub-index of sample for $i$ parameter exceeding permitted value; $R W i=$ relative weight of $i$ parameter; $R i, e=$ The ratio of samples exceeding permitted value of parameter $i$ to total number of samples of parameter $I ; n=$ number of control parameters

The sub-index (Equation (2)) is calculated according to measured physicochemical and microbiological water quality parameter values, standard values deriving from legislation limits, and desired or ideal values.

$$
q_{i}=\frac{100 \times\left|C_{i}-V_{i 0}\right|}{\left|S_{i}-V_{i 0}\right|}
$$

where: $C i=$ measured value of the $i$ water quality parameter; $S i=$ permitted $i$ water quality parameter value obtained from legislation; Vio $=$ the ideal value of $i$ water quality parameter.

The permitted values of control parameters were obtained from the limit values of European directives and national legislation regarding quality of internal surface, ground and drinking waters (Directive 75/440/EEC [7], Directive 98/83/EC [8], Greek Legislation 189/B/68 [9], Directive 78/659/EEC [10], Greek Legislation 354/B/11 [11], Greek Legislation 797/B/01 [12]).

For ideal values, the Lower Detection Limit (LDL) of each parameter, as defined by Directive 98/83/EC [8], was used.

For the selection of the control parameters that should be included into the calculation of $\Upsilon \triangle \Omega P W Q I$ and for the definition of weight coefficients, the Delphi method was applied. Two appropriate questionnaires were compiled; the first one was sent to approximately 1000 Water Management Agencies, Water Supply Companies, Relevant Ministries, Research Institutes and Universities, National, European and International Organizations and to Non-Governmental Organizations, globally. The respondents were asked to choose among 67 parameters (Table 1) to be included in $\Upsilon \triangle$ QPWQI having the following options "mandatory", "optional", "should not be included" and "not sure". The parameters were selected from the Environmental Quality Standards (EQS) [13] and from the priority substances, as defined in Directive 2000/60/EC [14]. The respondents had the option to propose additional parameters, which they considered important and were not included in the questionnaire.

Subsequently, a second questionnaire was sent to the 180 responders of the first questionnaire, asking them to rate the significance of each parameter by assigning a weight score (AWS) in a range from 1 (low significance) to 5 (high significance). They were also asked to specify three pollutants that are often present in their region and require systematic monitoring. The list of parameters and their assigned weights is presented in table 1.

The assigned weight $(A W i)$ of each parameter was calculated using Equation (3). 


$$
A W i=\frac{\sum A W S i j}{n}
$$

where $A W S i j=$ assigned weight score of $i$ parameter from the $j$ respondent; $n=$ the number of respondents.

The relative weight $(R W)$ of each included parameter was calculated by Equation (4).

$$
R W=\frac{A W i}{\sum_{i=1}^{n} A W i}
$$

where $R W i=$ the relative weight of $i$ parameter; $A W i=$ the assigned weight of of $i$ parameter.

\begin{tabular}{|c|c|c|c|c|c|c|c|c|}
\hline No & Parameter & AW & No & Parameter & AW & No & Parameter & AW \\
\hline 1 & Chromium (VI) & 4.78 & 24 & BOD & 3.99 & 47 & Radium & 3.52 \\
\hline 2 & E-coli & 4.77 & 25 & $\mathrm{pH}$ & 3.96 & 48 & Aluminium & 3.47 \\
\hline 3 & Lead & 4.73 & 26 & Benzene & 3.94 & 49 & Chlorides & 3.44 \\
\hline 4 & Arsenic & 4.72 & 27 & Chromium (III) & 3.94 & 50 & Vinyl Chloride & 3.44 \\
\hline 5 & Cadmium & 4.71 & 28 & Nickel & 3.93 & 51 & TSS & 3.74 \\
\hline 6 & Fecal Coliforms & 4.67 & 29 & Ps. Aeraginosa & 3.93 & 52 & Acrylamide & 3.39 \\
\hline 7 & Total Pesticides & 4.67 & 30 & Manganese & 3.91 & 53 & TDS & 3.38 \\
\hline 8 & Mercury & 4.57 & 31 & Surfactants & 3.90 & 54 & Hardness & 3.36 \\
\hline 9 & Ammonium & 4.43 & 32 & Mineral Oil & 3.99 & 55 & Radioactive Cesium & 3.34 \\
\hline 10 & COD & 4.38 & 33 & Copper & 3.81 & 56 & Color & 3.33 \\
\hline 11 & Salmonella & 4.36 & 34 & Zinc $(\mathrm{Zn})$ & 3.80 & 57 & Potassium & 3.29 \\
\hline 12 & Nitrite Ions & 4.35 & 35 & Dissolved Oxygen & 3.78 & 58 & Sodium & 3.28 \\
\hline 13 & Nitrate Ions & 4.34 & 36 & Selenium & 3.77 & 59 & Radioactive Iodine & 3.27 \\
\hline 14 & Total Phosphorus & 4.28 & 37 & Conductivity & 3.76 & 60 & Tritium & 3.27 \\
\hline 15 & PCB's-PCT's & 4.18 & 38 & Antimony & 3.74 & 61 & Silver & 3.23 \\
\hline 16 & Volatile Organic Comp. & 4.16 & 39 & TKN & 3.72 & 62 & Turbidity & 3.17 \\
\hline 17 & Phenols & 4.12 & 40 & Total Tri-alomethanes & 3.67 & 63 & Magnesium & 3.06 \\
\hline 18 & PAH's & 4.06 & 41 & Fat. Oil \& Grease & 3.62 & 64 & Alkalinity & 2.94 \\
\hline 19 & Clostridium P. & 4.06 & 42 & Uranium & 3.59 & 65 & Calcium & 2.72 \\
\hline 20 & Phosphates & 4.06 & 43 & Ferrous & 3.56 & 66 & Radon & 3.62 \\
\hline 21 & Residual Chlorine & 4.06 & 44 & Gamma ray & 3.56 & 67 & Temperature & 2.52 \\
\hline 22 & TOC & 4.01 & 45 & Alpha \& Beta rays & 3.52 & & & \\
\hline 23 & Total Coliforms & 4.00 & 46 & Sulfates & 3.52 & & & \\
\hline
\end{tabular}

Table 1. List of parameters and assigned weights in order of decreasing importance.

The final selection of the parameters, included in $\Upsilon \Delta \Omega P W Q I$, was based on the AWs of each parameter; the statistical results from the questionnaire regarding which parameters must be included "mandatory" or "optionally" in a WQI and the proposed additional parameters suggested by the respondents.

Therefore, the choice of the parameters which must be included in $\Upsilon \Delta \Omega P W Q I$ was made by initially excluding the parameters that had an $\mathrm{AW}<4$, and subsequently the parameters that were considered by the $70 \%$ of the respondents as "mandatory". Furthermore, the parameter that was proposed as the most frequently encountered in Greece and requires systematic monitoring is Chlorides, because of the pollution problems due to salinization phenomena. Consequently, it was considered necessary to include the parameter of Chlorides in the final calculation parameters of $\Upsilon \triangle \Omega P W Q I$, as the problem of salinization is intense both in Greece and other countries. The parameter of Phosphates was excluded, because it was considered of lower significance than the parameter of Total Phosphorus that was included. The parameter of total coliforms (TC) was also excluded, since fecal coliforms, which are a group of TC, are considered more hazardous and

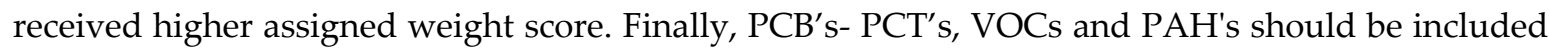
only in cases that they are encountered in the examined area, due to the high cost and the time-consuming analysis methods. Consequently, 17 parameters were included in the calculation of $\Upsilon \triangle \Omega P W Q I$, as presented in Table 2. 
Table 2. Final Parameters of $\Upsilon \Delta \Omega P W Q I$.

\begin{tabular}{ccc}
\hline & Parameter & AW \\
\hline 1 & Chromium (VI) & 4.78 \\
2 & E-coli & 4.77 \\
3 & Lead & 4.73 \\
4 & Arsenic & 4.72 \\
5 & Cadmium & 4.71 \\
6 & Fecal Coliforms & 4.67 \\
7 & Total Pesticides & 4.67 \\
8 & Mercury & 4.57 \\
9 & Ammonium & 4.43 \\
10 & COD & 4.38 \\
11 & Nitrite Ions & 4.35 \\
12 & Nitrate Ions & 4.34 \\
13 & Total Phosphorus & 4.28 \\
14 & PCB's-PCT's & 4.18 \\
15 & Volative Organic Comp. & 4.16 \\
16 & PAH's & 4.06 \\
17 & Chlorides & 3.44 \\
\hline
\end{tabular}

$\Upsilon \triangle \Omega P W Q I$ classifies water quality as Excellent, Good, Fair, Marginal and Poor, based on the calculated numerical result. The classification of water quality according to $\Upsilon \Delta \Omega P W Q I$ is presented in Table 3. This classification has been modified since its previous version [4], in order to improve the accuracy of the characterization results.

Table 3. $\Upsilon \Delta \Omega P W Q I$ characterization of water quality.

\begin{tabular}{cc}
\hline $\boldsymbol{\Upsilon \Delta} \Omega$ PWQI & Category \\
\hline $0-10$ & Excellent \\
$>10-25$ & Good \\
$>25-50$ & Fair \\
$>50-100$ & Marginal \\
$>100$ & Poor \\
\hline
\end{tabular}

\section{Results and Discussion}

The application of $\Upsilon \Delta \Omega P W Q I$ was conducted for surface waters of Aliakmon's river basin, which is the longest river in Greece. $\Upsilon \triangle \Omega P W Q I$ was applied using the data base of the accredited according to ISO 17025 research Laboratory of Environmental Chemistry and Water and Wastewater Treatment, at the University of Western Macedonia, Greece, for the parameters of Chromium Hexavalent, E-coli, Fecal Coliforms, Ammonium, COD, Nitrite Ions, Nitrate Ions and Chlorides. In total, 47 samples from 16 sample stations were analyzed concerning the period 2018-2019.

Regarding the parameters of Total Pesticides, Lead, Arsenic, Cadmium, and Mercury the data base of the Greek Ministry of Rural Development and Food was used [15].

\subsection{Application of $\Upsilon \triangle \Omega P W Q I$}

After the determination of the water quality parameters and the RW for each one of them, $\Upsilon \triangle \Omega P W Q I$ was applied on the available water quality data for Aliakmon river basin. In Table 4 the calculated RW, the permitted values $(S i)$ and the ideal values $\left(V_{i o}\right)$ used for calculating $\Upsilon \Delta \Omega P W Q I$ are presented.

The result of $\Upsilon \Delta \Omega P W Q I$ application on Aliakmon's river basin surface waters is presented in Table 5. According to the measured physicochemical and microbiological characteristics, the surface water of Aliakmon river basin is classified as Good. According to the previous version of $\Upsilon \Delta \Omega P W Q I$ the surface water of Aliakmon river basin is classified as Excelled $(\Upsilon \Delta \Omega P W Q I=10.95)$. 
Table 4. Relative Weight values $(R W)$, permitted values $(S i)$ and ideal values $\left(V_{i o}\right)$ used for the calculation of $\Upsilon \Delta \Omega P W Q I$.

\begin{tabular}{ccccc}
\hline Parameter & Rwi & Permitted Values (mg/L) & Ideal Values (mg/L) & Reference \\
\hline Chromium (VI) & 0.076 & 0.03 & 0.003 & 12 \\
E-coli & 0.076 & 20 & 0 & 9 \\
Lead & 0.075 & 0.02 & 0.002 & 12 \\
Arsenic & 0.075 & 0.03 & 0.003 & 12 \\
Cadmium & 0.075 & 0.005 & 0.0005 & 9 \\
Fecal Coliforms & 0.074 & 20 & 0 & 9 \\
Total Pesticides & 0.074 & 0.0025 & 0.000625 & 9 \\
Mercury & 0.073 & 0.001 & 0.0002 & 9 \\
Ammonium & 0.07 & 0.643 & 0.0643 & 12 \\
COD & 0.07 & 30 & 3 & 9 \\
Nitrite Ions & 0.069 & 0.1 & 0.01 & 12 \\
Nitrate Ions & 0.069 & 50 & 5 & 9 \\
Total Phosphorus & 0.068 & 0.015 & 0.0015 & 12 \\
Chlorides & 0.055 & 200 & 20 & 9 \\
\hline
\end{tabular}

Table 5. Calculation of $\Upsilon \Delta \Omega P W Q I$ in Aliakmon's river basin.

\begin{tabular}{|c|c|c|c|c|c|}
\hline Parametrer & Rwi & Average qi & $q i^{*} R w i$ & Average qi,e & Ri,e* qi* Rwi,e \\
\hline $\mathrm{Cr}(\mathrm{VI})$ & 0.076 & 6.05 & 0.46 & 0.00 & 0.00 \\
\hline e-coli & 0.076 & 5.00 & 0.38 & 0.00 & 0.00 \\
\hline $\mathrm{Pb}$ & 0.075 & 0.53 & 0.04 & 0.00 & 0.00 \\
\hline As & 0.075 & 0.00 & 0 & 0.00 & 0.00 \\
\hline $\mathrm{Cd}$ & 0.075 & 1.07 & 0.08 & 0.00 & 0.00 \\
\hline Fecal Coliforms & 0.074 & 6.76 & 0.5 & 0.00 & 0.00 \\
\hline Total Pesticides & 0.074 & 0.00 & 0 & 0.00 & 0.00 \\
\hline $\mathrm{Hg}$ & 0.073 & 67.81 & 4.95 & 55.41 & 4.05 \\
\hline Ammonium & 0.07 & 2.86 & 0.2 & 0.00 & 0 \\
\hline COD & 0.07 & 19.86 & 1.39 & 5.86 & 0.41 \\
\hline Nitrite Ions & 0.069 & 36.67 & 2.53 & 24.49 & 1.69 \\
\hline Nitrate Ions & 0.069 & 0.29 & 0.02 & 0.00 & 0.00 \\
\hline $\mathrm{TP}$ & 0.068 & 2.35 & 0.16 & 0.00 & 0.00 \\
\hline Chlorides & 0.055 & 4.36 & 0.24 & 4.36 & 0.24 \\
\hline SUM & 1 & & 10.95 & & 6.39 \\
\hline$\Upsilon \Delta \Omega P W Q I:$ & \multicolumn{5}{|c|}{$17.34=$ Good } \\
\hline
\end{tabular}

\subsection{Comparison of $\Upsilon \triangle \Omega P W Q I$ with Other WQIs}

The values of $\Upsilon \triangle \Omega P W Q I$ were compared to those of modified NSFWQI and CCMEWQI, the results are showed in Table 6.

Table 6. Comparison of $\Upsilon \triangle \Omega P W Q I$ to NSFWQI and CCMEWQI.

\begin{tabular}{ccc}
\hline Modified NSFWQI & CCMEWQI & $\Upsilon \Delta$ SPWQI \\
\hline 15.25 & 83.43 & 17.34 \\
Excellent & Good & Good \\
\hline
\end{tabular}

The calculation of NSFWQI and CCMEWQI was made for the same parameters. The result of $\Upsilon \triangle \Omega P W Q I$ is similar to CCMEWQI, and comparable to modified NSFWQI, which characterizes the quality of surface water as "Excellent". The calculation of CCMEWQI is based on the percentage of control parameters that present transgressions, on the percentage of the individual tests that do not meet the permitted values and on the deviations from the permitted values. For the calculation of 
modified NSFWQI the same weight coefficients with $\Upsilon \triangle \Omega P W Q I$ were applied. The observed differentiations between $\Upsilon \triangle \Omega P W Q I$ and modified NSFWQI are attributed to the fact that $\Upsilon \triangle \Omega P W Q I$ is taking into account in its calculation the ideal values, as well as the transgressions.

\section{Conclusions}

Water quality indices are useful tools for the assessment of water quality and water management. Since the first similar study, contacted in 1970, water quality control parameters and their permitted values has changed. $\Upsilon \triangle \Omega P W Q I$ is a new, sensitive and flexible tool that prioritizes monitoring parameters, redefines weight coefficients and inserts in its calculation the ideal values. $\Upsilon \triangle \Omega P W Q I$ can characterize the quality of a water body more accurately by taking into consideration both legislation and expert's opinion, and is more sensitive to marginal conditions, in contrast to other indices (CCMEWQI and NSF). Its flexibility lies in the fact that $\Upsilon \triangle \Omega P W Q I$ can be easily modified in order to cover the needs and specificities of an area.

Author Contributions: Conceptualization, A.E. and T.L.; methodology, T.E. and S.G.; software, M.C.; validation, L.L. and M.C.; formal analysis, S.G.; investigation, M.C. and S.G.; resources, T.E.; data curation, M.C.; writing-original draft preparation, M.C.; writing - review and editing, A.E. and S.G.; supervision, A.E., T.L. and T.E.; project administration, A.E. and P.G.; funding acquisition, A.E. All authors have read and agree to the published version of the manuscript.

Funding: This research was funded by "Interreg IPA II Cross-border Cooperation Programme Greece-Albania 2014-2020".

Conflicts of Interest: The authors declare no conflict of interest. The funders had no role in the design of the study; in the collection, analyses, or interpretation of data; in the writing of the manuscript, or in the decision to publish the results.

\section{References}

1. Abbassi, T.; Abbassi, S.A. Water Quality Indices; Elsevier: Kidlington Oxford, UK, 2012; pp. 4-63, doi:10.1007/s12665-014-3141-9.

2. Trikoilidou, E.; Samiotis, G.; Tsikritzis, L.; Kevrekidis, T.; Amanatidou, E. Evaluation of Water Quality Indices Adequacy in Characterizing the Physico-Chemical Water Quality of Lakes. Environ. Process. 2017, 1, S35-S46, doi:10.1007/s40710-017-0218-y.

3. Zotou, I.; Tsihrintzis, V.; Gikas, G. Water quality evaluation of a lacustrine water body in the Mediterranean based on different water quality index (WQI) methodologies. J. Environ. Sci. Health 2019, 55, 537-548, doi:10.1080/10934529.2019.1710956.

4. Iakovidou, F.; Trikoilidou, E.; Samiotis, G.; Stamos, A.; Tsikritzis, L.; Amanatidou, E. Development of An Updated Water Quality Index Based on Legislation and Experts' Opinion. In Proceedings of the 10th World Congress of EWRA 'Panta Rhei', Athens, Greece, 5-9 July 2017; European Water Resources Association: Athens, Greece, 2017.

5. Kumar Sajil, P.J.; James, E.J. Development of Water Quality Index (WQI) model for the groundwater in Tirupur district, South India. Chin. J. Geochem. 2013, 32, 261-268, doi:10.1007/s11631-013-0631-5.

6. Canadian Council of Ministers of the Environment. Canadian Water Quality Guidelines for the Protection of Aquatic Life: CCME Water Quality Index 1.0, User's Manual. In Canadian Environmental Quality Guidelines; Canadian Council of Ministers of the Environment: Winnipeg, MB, Canada, 2001.

7. Council Directive 75/440/EEC of 16 June 1975 concerning the quality required of surface water intended for the abstraction of drinking water in the Member States. Off. J. Law 1975, 194, 26-31.

8. Council Directive 98/83/EC of 3 November 1998 on the quality of water intended for human consumption. Off. J. Eur. Commun. 1998, 330, 32-54, Brussels.

9. M.D. Г3a)761, Sanitary provision on the quality of drinking water. Greek Government Gazette: Athens, Greece, 1968; B'189/10-4-1968.

10. Council Directive 78/659/EEC on the quality of fresh waters needing protection or improvement in order to support fish life. Off. J. Eur. Commun. 1978, 222, 1-10, Brussels.

11. Joint Ministerial Decision 145116/02-02-2011, Settlement of Measures, Conditions and Procedures for the Waste Water Reuse and Other Clauses; Greek Government Gazette B: Athens, Greece, 2011; 354/8-3-2011. 
12. Common Ministerial Decision CMD15782/1849/25-06-2001. Special Programme for Water Pollution Reduction for The Lakes Vegoritis, Petron and the Soulou River Caused By Hazardous Substances; Greek Government Gazette: Athens, Greece, 2001; B'797/25-06-2001.

13. Directive 2008/105/EC of the European Parliament and of the Council of 16 December 2008 on environmental quality standards in the field of water policy, amending and subsequently repealing Council Directives 82/176/EEC, 83/513/EEC, 84/156/EEC, 84/491/EEC, 86/280/EEC and amending Directive 2000/60/EC of the European Parliament and of the Council. Off. J. Eur. Commun. 2008, 348, 84-97, Brussels.

14. European Parliament and the Council of the European Union Directive 2000/60/EC 2000. Water Framework Directive. Off. J. Eur. Commun. 2000, 327, 1-73, Brussels.

15. Ministry of Rural Development and Food of Greece. Monitoring of Chemical Quality of Water (Surface and Groundwater) for Irrigation on a River Basin Scale for the Rivers of Macedonia, Thrace and Thessaly, Greece: Results for Aliakmon River Basin. (In Greek). Available online: http://www2.minagric.gr/ardeftika/files/results/geol/15.RESULTS_ALIAKMONA.pdf (accessed on 1 January 2020).

(C) 2020 by the authors. Licensee MDPI, Basel, Switzerland. This article is an open access article distributed under the terms and conditions of the Creative Commons Attribution (CC BY) license (http://creativecommons.org/licenses/by/4.0/). 